\title{
Field performance and survival of cocoa seedlings raised in different growing media
}

\author{
M. M. AKPALU,${ }^{1 *}$ G. K. OFOSU-BUDU, ${ }^{2}$ F. K. KUMAGA, ${ }^{2}$ \\ K. OFORI, ${ }^{2}$ L. MINTAH ${ }^{3}$ \\ ${ }^{1}$ Department of Ecological Agriculture, Bolgatanga Technical University, \\ Bolgatanga - UE Region, Ghana \\ ${ }^{2}$ Department of Crop Science University of Ghana, Legon - Accra \\ ${ }^{3}$ Forest and Horticultural Research Centre - Okumaning, Kade \\ e-mail: aa.marilyn@yahoo.com, obuduster@gmail.com, fkumaga@ug.edu.gh, \\ kofori@wacci.ug.edu.ug, lomintah@ug.edu.gh
}

Manuscript received 30 July 2021; revised 10 September 2021;

accepted 22 September 2021

\begin{abstract}
The medium from which seedlings are transplanted influences seedling growth and survival on the field. The objective of the experiment was to compare how growing media affect the growth and survival of cocoa seedlings under field conditions. The seedlings were raised in both soil and soilless media and were transplanted on the field in June, when they were six months old. The experimental design was a randomized complete block design with three different growing media: 1 . top soil, 2 . sawdust + poultry manure + rice husk biochar $(70 \%: 25 \%: 5 \%)$, and 3 . sawdust + poultry manure + municipal solid waste compost (50\%:35\%:15\%). The cocoa seedlings were transplanted at a spacing of $3 \mathrm{~m} \times 3 \mathrm{~m}$ at 12 plants per plot and each plot size measured $45 \mathrm{~m}$ x $45 \mathrm{~m}$. Data were collected on plant height, leaf number, stem girth, leaf chlorophyll content, percentage of plants that shed their leaves, and percentage of survival. Results indicated that seedling survival at the onset and end of the dry season was significantly $(\mathrm{P}<0.05)$ higher for seedlings transplanted from soilless media compared to those from the top soil treatment. Irrigation will be necessary to maintain high seedling survival when seedlings are transplanted from the top soil for a well-established plantation.
\end{abstract}

Keywords: cocoa, growing media, transplanting, survival 


\section{Introduction}

The survival of seedlings at transplanting is partly dependent on the medium from which seedlings are transplanted. Poor-quality seedlings at the juvenile stage may result in the poor establishment of seedlings on the field, slow growth, and reduced survival percentage [1]. Soon after transplanting, seedlings essentially depend on active root water uptake, and when the leaf area increases, water demand also increases due to evapotranspiration. At this point, transplanted seedlings tend to rely heavily on root growth [2]. In Ghana, and in Africa in general, cocoa seedlings are mainly transplanted in June, when the rainfall is frequent and peaks in October [3]. In October, leaf development may be intense due to high rainfall. However, shortly after the dry season sets in in November, decrease in soil moisture at this period of growth results in high seedling mortality since plants are very sensitive to moisture stress at this stage [4]. Rapid root growth and ability to tap water during this phase of growth is vital to seedling survival and early establishment. The nursery growth medium that enhances root development would subsequently support agile root development after transplanting, thus the ability of the seedling to acclimatize in the new environment. Seedlings experience more drought when grown on organic soils as compared to soilless substrates [5], as the later enhances good root development. We, therefore, hypothesise that seedlings transplanted from soilless media will perform better on the field than those from the soil.

The aim of this study was to compare the growth performance and survival of seedlings transplanted from soil and soilless growing media.

\section{Methodology}

Experimental site: The experiment was carried out at the University of Ghana's Forest and Horticultural Research Centre - Okumaning ( $6^{0} 05^{\prime} \mathrm{N} ; 0^{0} 05^{\prime}$ W), near Kade, in the Eastern Region. The centre is located about $175 \mathrm{~km}$ from Accra and about 150 $\mathrm{m}$ above sea level. It is located in the moist semi-deciduous vegetation zone of Ghana.

Experimental design and treatments: The experimental design was a randomized complete block design (RCBD) with five replications. Seedlings used for the study were raised in different growing media for five months. These were: 1 . top soil (control), 2. sawdust + poultry manure + rice husk biochar (70\%:25\%:5), and 3 . sawdust + poultry manure + municipal solid waste compost (50\%:35\%:15\%).

Land preparation: The site has been previously cropped with plantain. Slashing was done after the few cocoa and rubber plants were felled and cleared. Stumps were removed using a pickaxe and packed at the edge of the field, and leaves were allowed to rot. The land was left for three weeks, during which the appearing weeds were sprayed with glyphosate. After the weeds died off, the site was divided into three blocks with three replications, which were lined and pegged. 
Soil sampling: Soil samples were collected randomly at six different points in the field, using an auger, at the depths of $0-20 \mathrm{~cm}$ and $20-40 \mathrm{~cm}$. The samples were taken to the laboratory to analyse their chemical and physical properties.

Plantain as shade tree: Plantain suckers obtained from the FOHCREC nursery by way of plantain sucker multiplication in polybags had been planted one-two months before the cocoa seedlings were transplanted, so as to serve as shade trees for the young cocoa seedlings.

Transplanting: Six-month-old cocoa seedlings were transplanted at a spacing of $3 \mathrm{~m} \times 3 \mathrm{~m}$ into holes that were dug $25 \mathrm{~cm}$ deep. Polybags were removed carefully in order not to lose the medium around the root. The seedlings, together with the ball of growing media, were placed in the holes and covered firmly. A plot consisted of fifteen plants ( $5 \times 3$ planted in a rectangular pattern), and data were taken on the seedlings in the middle, bordered by 12 plants. Each plot measured $45 \mathrm{~m} \times 45 \mathrm{~m}$, was contiguous to other treatment plots, and the distance between plots was $3 \mathrm{~m}$. The experiment was replicated three times with 180 plants per replicate, making a total of 540 plants occupying an area of $72 \mathrm{~m} \times 72 \mathrm{~m}$.

Parameters measured: Plant height: This was measured using a metre rule; measurement was taken from the base of the plant to the apex. Leaf number: This was recorded by counting the total number of leaves per plant. Stem girth: This was measured $15 \mathrm{~cm}$ above the ground using electronic calliper. Chlorophyll content: This was measured using SPAD chlorophyll metre, and the leaf chlorophyll content was measured on the forth leaf from the apex at each side of the midrib. Plants that had fully shed their leaves were counted and divided by the total number of plants per plot. Percentage of survival: This was recorded by counting the number of plants alive divided by the total number of seedlings transplanted per plot multiplied by 100 .

\section{Results}

Table 1. Climatic data between June and December 2018

\begin{tabular}{lccccccc}
\hline Months & $\begin{array}{c}\text { Mean } \\
\text { rainfall } \\
(\mathbf{m m})\end{array}$ & $\begin{array}{c}\text { Mean } \\
\text { temperature }\left({ }^{\mathbf{C}} \mathbf{C}\right)\end{array}$ & & Mean RH (\%) & $\begin{array}{c}\text { Solar } \\
\text { radiation } \\
\left(\mathbf{M J ~ m}^{-2}\right)\end{array}$ & $\begin{array}{c}\text { Mean wind } \\
\text { speed (m/s) }\end{array}$ \\
\hline & & Max. & Min. & $\begin{array}{c}\text { Max. } \\
\text { (Night) }\end{array}$ & $\begin{array}{c}\text { Min. } \\
(\text { Day) }\end{array}$ & & \\
\hline June & 257.8 & 31.7 & 22.0 & 100.0 & 62.2 & 13.8 & 0.30 \\
\hline July & 110.8 & 30.6 & 22.6 & 100.0 & 66.2 & 10.4 & 0.27 \\
\hline August & 86.6 & 30.5 & 21.7 & 99.7 & 63.1 & 10.4 & 0.29 \\
\hline September & 213.4 & 31.3 & 22.2 & 100.0 & 63.6 & 10.7 & 0.30 \\
\hline October & 245.5 & 33.1 & 22.2 & 100.0 & 58.8 & 13.8 & 0.29 \\
\hline November & 92.2 & 33.4 & 22.0 & 100.0 & 59.1 & 14.0 & 0.27 \\
\hline December & 21.8 & 33.6 & 21.8 & 99.8 & 48.5 & 13.0 & 0.25 \\
\hline
\end{tabular}


Table 2a. Soil physicochemical properties

\begin{tabular}{lccc}
\hline Soil depth & $\mathbf{0 - 2 0} \mathbf{~ c m}$ & $\mathbf{2 0 - 4 0} \mathbf{~ c m}$ & t-statistic \\
\hline Porosity (\%) & 60.50 & 57.33 & 0.003 \\
Bulk density $\left(\mathrm{g} / \mathrm{cm}^{3}\right)$ & 1.15 & 1.16 & 0.721 \\
$\mathrm{pH}$ & 6.1 & 5.9 & 0.312 \\
$\mathrm{Ec}(\mathrm{dS} / \mathrm{m})$ & 0.072 & 0.040 & 0.221 \\
$\mathrm{OC}(\%)$ & 2.99 & 1.798 & 0.042 \\
$\mathrm{OM}(\%)$ & 5.99 & 3.08 & 0.003 \\
$\mathrm{TN}(\%)$ & 0.0083 & 0.0061 & 0.004 \\
$\mathrm{AP}(\mathrm{mg} / \mathrm{kg})$ & 21.53 & 17.27 & 0.047 \\
$\mathrm{~K}$ & 0.515 & 0.145 & $<0.001$ \\
$\mathrm{NH}_{4}-\mathrm{N}(\mathrm{mg} / \mathrm{kg})$ & 2.480 & 1.558 & 0.011 \\
$\mathrm{NO}_{3}$-N (mg/kg) & 1.082 & 0.920 & 0.072 \\
\hline
\end{tabular}

Table 2b. Exchangeable bases

\begin{tabular}{cccccc}
\hline $\begin{array}{c}\text { Soil } \\
\text { depth }\end{array}$ & $\begin{array}{c}\mathrm{Ca} \\
(\mathbf{c m o l}(+) / \mathbf{k g})\end{array}$ & $\begin{array}{c}\mathrm{Mg}(\mathbf{c m o l}(+) / \\
\mathbf{k g})\end{array}$ & $\begin{array}{c}\mathrm{K} \\
(\mathbf{c m o l}(+) / \mathbf{k g})\end{array}$ & $\begin{array}{c}\mathrm{Na}(\mathbf{c m o l}(+) / \\
\mathbf{~ k g})\end{array}$ & $\begin{array}{c}\mathrm{CEC}(\mathbf{c m o l}(+) / \\
\mathbf{~ k g})\end{array}$ \\
\hline $0-20$ & $4.47( \pm 1.01)$ & $3.18( \pm 1.27)$ & $0.49( \pm 0.09)$ & $0.01( \pm 0.00)$ & $12.53( \pm 2.57)$ \\
$20-40$ & $1.01( \pm 0.35)$ & $1.43( \pm 0.53)$ & $0.10(0.00)$ & $0.01( \pm 0.00)$ & $6.58( \pm 2.22)$ \\
\hline
\end{tabular}

\section{Influence of growing media on cocoa seedling stem girth and field establishment}

At transplanting, the stem girth was significantly $(\mathrm{p}=0.007)$ bigger for $\mathrm{SD}+\mathrm{PM}+$ RHB (9.24 mm), followed by top soil $(7.65 \mathrm{~mm})$ and SD + MSWC + RHB (7.44 mm), but there was no significant difference between the top soil treatment and that of SD + MSWC + RHB. One month after transplanting (MAT), no significant ( $\mathrm{p}=$ 0.052 ) treatment effect was observed on the stem diameter, the top soil and SD + MSWC + RHB were on a par with the SD + PM + RHB-treated plants, and it was similar with 2 MAT. However, at 3 MAT, significant $(p=0.007)$ differences were recorded: SD + PM + RHB-treated seedlings recorded bigger stem girth (12.70 mm) than both top soil and SD + MSWC + RHB (1.20 and $1.20 \mathrm{~mm}$ ). From 4 MAT to 6 MAT, no significant treatment effect was recorded (Figure 1). 


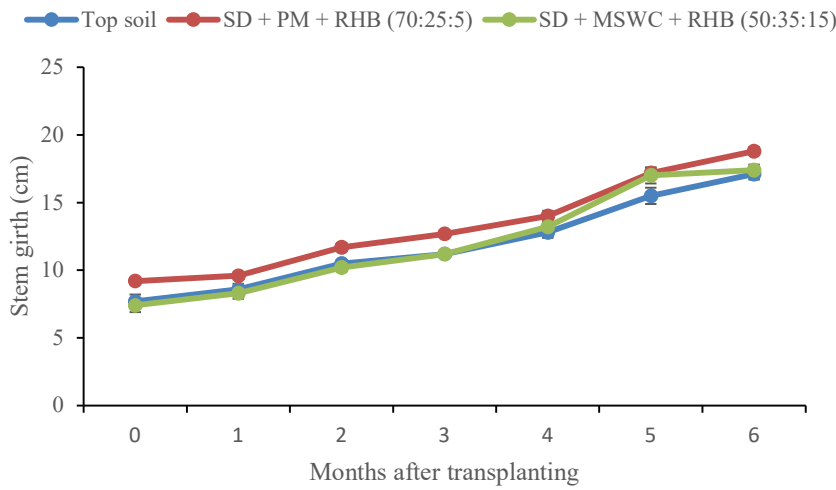

Figure 1. Influence of growing media on cocoa seedling stem girth and field establishment

\section{Influence of growing media on the leaf number and field establishment of cocoa}

Leaf number at transplanting (0 MAT) was significantly $(\mathrm{p}=0.002)$ high for SD + PM + RHB (24.8) treated seedlings, followed by the top soil (18.2) and SD + MSWC + RHB (16.6). There were no significant treatment differences between the top soil and $\mathrm{SD}+\mathrm{MSWC}+\mathrm{RHB}$. The same trend was observed at $1 \mathrm{MAT}$, with SD + PM + RHB recording the highest leaf number $(\mathrm{p}=0.007)$. From 2, 3, 4, 5, and 6 MAT, there were no significant treatment differences recorded in the leaf number produced (Figure 2).

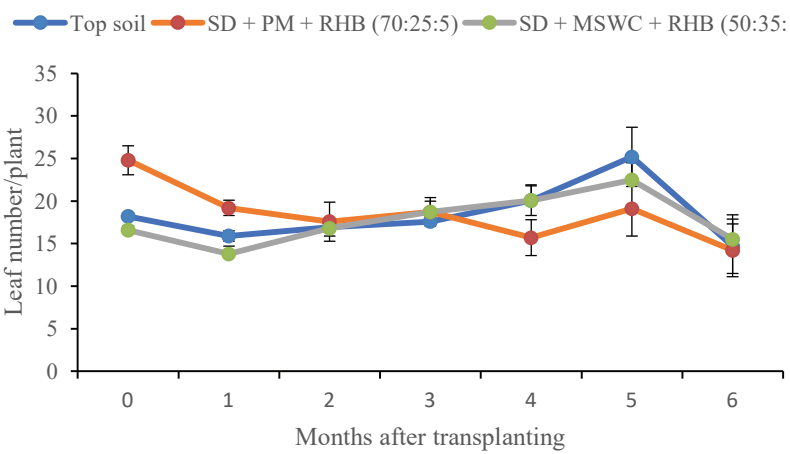

Figure 2. Influence of growing media on the leaf number and field establishment of cocoa 


\section{Influence of growing media on plant height under field conditions}

Significant $(\mathrm{p}<0.001)$ differences existed among growing media treatments in terms of plant height at transplanting, with SD + PM + RHB being the tallest (54.2 $\mathrm{cm})$ followed by top soil $(38.2 \mathrm{~cm})$ and SD + MSWC + RHB $(34.7 \mathrm{~cm})$. However, no significant difference was recorded at top soil and on SD + MSWC + RHB. The same trend was followed at 2 and 3 MAT. At 4 MAT, plant height for top soil and SD + MSWC + RHB increased almost on a par with SD + MSWC + RHB; hence, no significant $(p=0.302)$ difference was recorded among the growing media treatments. At $5 \mathrm{MAT}$ and $6 \mathrm{MAT}$, plant height for the three treatments was almost the same: top soil $(74.7 \mathrm{~cm})$, M2 $(75.5 \mathrm{~cm})$, and SD + MSWC + RHB $(71.8 \mathrm{~cm})$ (Figure 3).

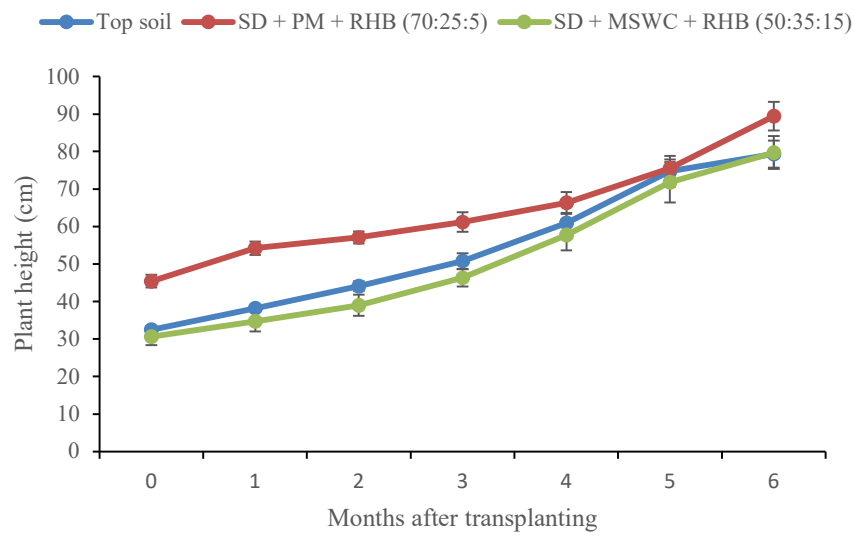

Figure 3. Influence of growing media on cocoa seedling height under field conditions

\section{Influence of growing media on the leaf chlorophyll content of cocoa under field conditions}

Throughout the six sampling periods, no significant $(\mathrm{P}>0.05)$ treatment effect was recorded. However, leaf chlorophyll content increased progressively from one month after transplanting, for all treatments, with SD + PM + RHB $(38.2 \mathrm{~cm})$ being slightly higher at 4 MAT, followed by top soil $(35.7 \mathrm{~cm})$ and SD + MSWC + RHB (33.2). At 5 MAT, the chlorophyll content of the top soil and of the SD + MSWC + RHB became slightly higher than that of the SD + PM + RHB. Then, at $6 \mathrm{MAT}$, the SD + PM + RHB $(45.6 \mathrm{~cm})$ became higher again, followed by the top soil $(39.9 \mathrm{~cm})$ and SD + MSWC + RHB $(33.6 \mathrm{~cm})$ treatments (Figure 4). 


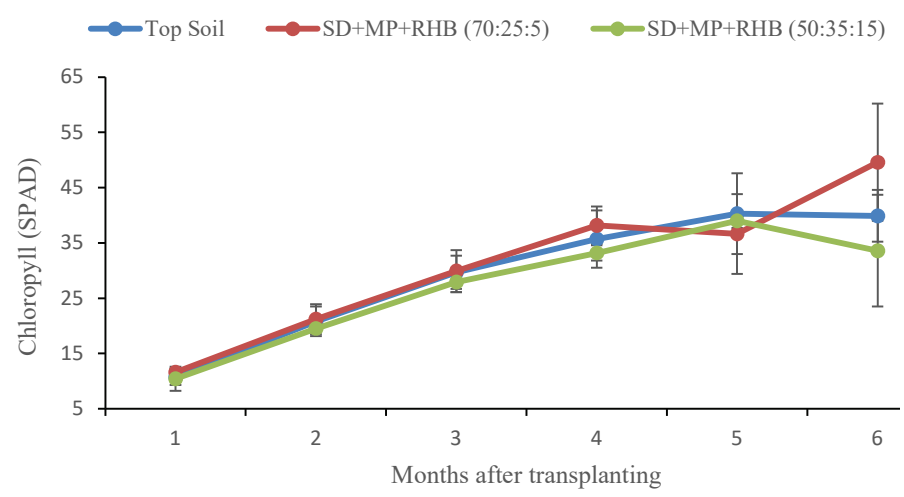

Figure 4. Influence of growing media on the leaf chlorophyll content of cocoa under field survival

\section{Influence of growing media on field survival and the establishment of cocoa at the onset of the dry season}

Some plants shed their leaves completely when the dry season started, and these were recorded as percentage per plot. Contrast showed significantly $(\mathrm{p}=0.009)$ more seedlings transplanted from top soil medium (26.7\%) shedding their leaves completely than those from SD + MSWC + RHB (6.7\%) and SD + PM + RHB (4.0\%) media treatments. The soilless media differed significantly $(\mathrm{p}=0.006)$ from the soil: more plants shed their leaves upon soil medium treatment than in soilless media.

The percentage of survival at the onset of the dry season was significantly $(\mathrm{p}=0.013)$ higher for SD + PM + RHB (91.3\%). Contrast established a significant $(\mathrm{p}=0.007)$ difference between the survival rate for seedlings transplanted from soilless media and those from the soil at the onset of the dry season. The soil moisture measurements within $20 \mathrm{~cm}$ soil depth differed significantly ( $\mathrm{p}=0.007)$, showing higher values at the root zone of soilless-media-treated plants compared to those of the top soil treatment. Similarly, at $40 \mathrm{~cm}$ depth, soil moisture was significantly $(\mathrm{p}=0.028)$ higher at the root zone of seedlings transplanted from the soilless media compared to those from the top soil (Table 3). The mean moisture content was significantly $(\mathrm{p}<0.01)$ higher at the $40 \mathrm{~cm}$ depth $(69.5 \pm 5.2) \mathrm{cm})$ than at the $20 \mathrm{~cm}$ depth $(29.9 \pm 2.5 \mathrm{~cm})($ Table 4$)$. 
Table 3. Influence of growing media on field survival and the establishment of cocoa at the onset of the dry season

\begin{tabular}{lccccc}
\hline Treatment & $\begin{array}{c}\text { Plants that } \\
\text { shed their } \\
\text { leaves (\%) }\end{array}$ & $\begin{array}{c}\text { Percentage } \\
\text { of survival } \\
\text { at the onset } \\
\text { of DS }\end{array}$ & $\begin{array}{c}\text { Percentage } \\
\text { of survival } \\
\text { after DS }\end{array}$ & $\begin{array}{c}\text { Soil moisture (mm) } \\
\text { (depth) }\end{array}$ \\
\hline & & & & $20 \mathrm{~cm}$ & $40 \mathrm{~cm}$ \\
\hline Top soil & $26.7 \pm 7.6$ & $74.1 \pm 2.7$ & $56.4 \pm 7.7$ & $19.0 \pm 1.2$ & $40.5 \pm 4.0$ \\
\hline $\begin{array}{l}\text { SD + PM + RHB } \\
\text { (70:25:5) }\end{array}$ & $4.0 \pm 2.7$ & $91.3 \pm 3.7$ & $78.3 \pm 4.7$ & $19.1 \pm 3.1$ & $48.0 \pm 6.7$ \\
\hline $\begin{array}{l}\text { SD + MSWC+ } \\
\text { RHB (50:35:15) }\end{array}$ & $6.7 \pm 3.0$ & $90.7 \pm 3.9$ & $89.3 \pm 3.0$ & $17.8 \pm 4.7$ & $33.8 \pm 7.9$ \\
\hline $\begin{array}{l}\text { Contrast } \\
\text { (P values) }\end{array}$ & & & & & \\
\hline Soil vrs soilless & 0.006 & 0.007 & 0.020 & $\mathrm{NS}$ & $\mathrm{NS}$ \\
\hline M2 vrs M7 & $\mathrm{NS}$ & $\mathrm{NS}$ & $\mathrm{NS}$ & $\mathrm{NS}$ & $\mathrm{NS}$ \\
\hline
\end{tabular}

Table 4. Statistics for soil moisture content at $20 \mathrm{~cm}$ and $40 \mathrm{~cm}$ at the onset of the dry season

\begin{tabular}{ccccc}
\hline Depth (cm) & Means (mm) & SE & t-statistic & P-value \\
\hline 20 & 18.6 & \pm 1.7 & & \\
\hline 40 & 40.8 & \pm 3.8 & -5.34 & $<0.001$ \\
\hline
\end{tabular}

\section{Discussion}

The soil analysis for the experimental site showed that the $\mathrm{pH}$ for the soil was slightly acidic, ranging from 5.9 to 6.1 , which was favourable for the growth of cocoa [6]. The ECs were very low, which was excellent for the growth of cocoa according to Bauder et al. (2010). High EC affects water availability to plants notwithstanding the wetness of the soil. Organic carbon and organic matter were moderate according to [7].

At the time of transplanting, the SD + PM + RHB (70:25:5) treatment was superior in terms of height, stem girth, and leaf number; this growth media also produced seedlings with a long taproot and larger root volume. This agrees with [2], who stated that the type of substrate in which seedlings are grown greatly affects seedling morphology and physiology and subsequently influences field establishment.

One month after transplanting, no significant differences were observed among the seedlings transplanted from the three different growing media, except for the 
leaf number, which was significant for SD + PM + RHB. This could be attributed to the fact that root development in top soil and SD + MSWC + RHB may have been restricted in the container in which they were grown. Nevertheless, when they were transplanted to the field, they had the chance to develop their root to exploit further resources to their growth advantage. The physiological condition of a seedling before transplanting is a reflection of its root growth potential under certain conditions and time (Mattsson, 1986). The significant leaf number observed for SD + PM + RHB may be due to the nutritional status of the seedling before transplanting. [8] studied nursery nitrogen loading on the field performance of oak seedlings and argued that a greater reserve of $\mathrm{N}$ and $\mathrm{K}$ in nursery plants may be capitalized on in the field to accommodate subsequent sink demand with the ability to improve seedling field performance and establishment. This served as evidence in the nutrient uptake of this medium, as leaf $\mathrm{N}, \mathrm{P}$, and $\mathrm{K}$ concentration was higher in soilless-media-treated plants compared to soil-medium-treated plants. Two and three months after transplanting, however, no significant differences were observed for stem girth and the produced leaf number among seedlings transplanted from the three growing media, except for seedling height, which was significant for SD + PM + RHB. According to [9], high-quality seedlings signify their genetic potential and display significant height growth in the first year of transplanting, as they are able to gain control of the site faster. From four to six months after transplanting, no significant growth trait differences were observed in the plants among the three growing media treatments. This might be due to root development out of the supporting medium from which they were transplanted and that they were now capable of exploiting the soil volume for water and nutrients. Once this advantage has been achieved, the plant is able to develop to its full potential. Therefore, the effect of the type of substrate used in the field performance of seedlings might be notable only at the early stages of the growth of transplanted seedlings, rather than at later stages. Environmental conditions, such as high temperature and low humidity, may cause excessive transpiration from leaf surfaces; the growing medium that attracts much moisture into the root zone of plants might be advantageous to withstanding transplanting shock. This might be the case for SD + PM + RHB in the earlier stages of transplanting.

The insignificant variations in leaf chlorophyll content among the growingmedia-treated plants after transplanting suggest that higher chlorophyll content was not necessarily a determinant of the growth of cocoa seedlings under field conditions. This is in line with [10], who pointed out that the chlorophyll fluorescence traits of cocoa leaf are indicators of extreme adaptation to shade conditions.

Nevertheless, the leaf chlorophyll content of the treatments increased over time, indicating the growth of the photosynthetic apparatus towards high demand for assimilates. In their experiment on the effects of temperature and light integral on early vegetative growth and the chlorophyll fluorescence of four contrasting 
genotypes of cocoa, [11] argued that the measurement of leaf chlorophyll content is a valuable approach to evaluating plant responses to their environment during early vegetative growth.

Some of the transplanted seedlings shed their leaves at the onset of the dry season, when they were exposed to moisture stress. This agrees with [12], who concluded that deciduous tree species alleviate the negative effects of water stress by shedding their leaves directly at the onset of the dry season. There was a decrease in the amount of rainfall, which marks the beginning of the dry season in December. The total amount of rainfall recorded in the month of December was relatively very low $(6.9 \mathrm{~mm})$ as compared to October $(245.5 \mathrm{~mm})$, the second peak period, and November (92.2 mm). Although soil moisture measured at the end of December at the root zone of the plants from different growing media did not differ significantly, there was significant variation in their leaf retention. More plants from the soil medium shed their leaves than from the soilless media treatment. Chidumayo (2001) [13] observed that dry-season leaf flourishing is the ability of plants' roots to access deeper soil water reserves and stem water storage capacity [14]. This might be the case for the soilless media treatments, as they developed bigger root volume during the nursery stage than the soil treatments. Therefore, continued root development after transplanting may have given the plants from the soilless growth media advantage over the topsoil-treated plants in accessing soil moisture under limited soil water conditions. The higher leaf shedding by plants under the soil medium treatment at the onset of the dry season is a typical survival mechanism of deciduous plant species. Karban (2017) [15] observed that shoots that hold their leaves throughout unfavourable conditions were more advantageous compared to those with their leaves removed since the latter were more likely to die. This is in line with Carr and Lockwood (2011), [16] performing irrigation and water requirement studies of cocoa and pointed out that cocoa seedlings under drought conditions showed symptoms of premature leaf drop progressively, from older leaves to the younger ones, including yellowing of primary leaves, reduced stem growth, decreased leaf formation, and wilting.

\section{Field survival at the onset of the dry season}

The relatively high percentage survival of seedlings of the soilless media treatment might be attributed to the development of larger root volume and longer taproot system. Moreover, this form of root development in the soilless medium may be supported by the inclusion of biochar in the medium. Mulcahy et al. (2013) [17] demonstrated that in sandy substrates $30 \%(\mathrm{v} / \mathrm{v})$ biochar - concentrated in the root zone of tomato seedlings - significantly increased seedling resistance to wilting for over 4,000 tomato seedlings each year. Similarly, Lu et al. (2014) [18] observed that addition of rice husk biochar (RHB) to expansive clayey soil (Vertisol) 
improved WHC and root penetration. High seedling survival for soilless media may also be due to the addition of poultry manure and MSWC. This finding is in line with other similar research [19], in which the effect of growing media on the seedling establishment of Terminalia bellirica was studied and which reported maximum survival rate of the seedlings transplanted from medium containing goat manure one year after establishment. The authors attributed it to the differences in the organic component of the growing medium. This may be the case in this study; the differences in the organic composition of the soilless substrate may have resulted in the high seedling survival. After the prolonged dry season, when rainfall became more frequent in June, the survival rate of soil-treated plants was found to be still low $(56.4 \pm 7.7 \%)$. At the onset of the dry season, while seedling survival was higher compared to the end of the dry season, farmers could intervene and irrigate their farms rather than wait for the following season's rainfall.

\section{Conclusions and recommendation}

Cocoa seedling growth and survival rate were enhanced under soilless media treatment as compared to those transplanted from the top soil. The cocoa seedling survival rate at the beginning and the end of the dry season points to the need to irrigate when the dry season starts, while soil moisture becomes depleted to maintain high seedling survival rate and improve establishment. Further research into soilless media effects on seedling survival and the establishment of cocoa would be required considering the mechanism of root development, stem water storage potential, and the hormonal differences in leaf retention under drought conditions.

\section{Acknowledgment}

The authors are grateful to Mr. Nana Oduro, Mr. John Danso, Mr. Addo Tettey, Mr. Mensah, and the staff of FOHCREC for their assistance in the research work and data collection. Our special appreciation goes to A. G. Leventis CBAS for funding the research.

\section{References}

[1] Nduka, B. A., Adewale, D. B., Akanbi, O. S. O., Adejobi, K. B. (2015), Nursery soil amendments for cashew seedling production: A comparative analysis of coffee husk and NPK. Journal of Agricultural Science 7(3), 111-122. https:// doi.org/10.5539/jas.v7n3p111.

[2] Kostopoulou, P., Dini-Papanastasi, O., Radoglou, K. (2010), Density and substrate effects on morphological and physiological parameters of plant stock 
material of four forest species grown in mini-plugs. Scandinavian Journal of Forest Research 25(supl. 8), 10-17. https://doi.org/10.1080/02827581.2 010.485826.

[3] Ofori, A., Konlan, S., Dadzie, M. A., Amoah, F. M. (2014), Genotypic performance of cocoa (Theobroma cacao L.) during establishment under natural drought stress. Journal of Crop Improvement 28(6), 804-824. https://doi.org/10.1080/1 5427528.2014 .947529$.

[4] Engelbrecht, B. M. J., Kursar, T. A. (2003), Comparative drought-resistance of seedlings of 28 species of co-occurring tropical woody plants. Oecologia 136(3), 383-393. https://doi.org/10.1007/s00442-003-1290-8.

[5] Pröll, G., Hietz, P., Delaney, C. M., Katzensteiner, K. (2016), Substrate influences ecophysiological performance of tree seedlings. Tree Physiology 36(1), 39-53. https://doi.org/10.1093/treephys/tpv104.

[6] Ogunride, I. S. (2006), Permanent Crop Production (ed. by Adebanjo, L.). National Open University of Nigeria, Lagos.

[7] Paramananthan, S. (1987), Soil suitability and management implications of soil taxonomy with special reference to tree crop cultivation. Pertanika Journal of Tropical Agricultural Science 10(2), 125-134.

[8] Salifu, K. F., Jacobs, D. F., Birge, Z. K. D. (2009), Nursery nitrogen loading improves field performance of bareroot oak seedlings planted on abandoned mine lands. Restoration Ecology 17(3), 339-349. https://doi.org/10.1111/ j.1526-100X.2008.00373.x.

[9] Davis, A. S., Jacobs, D. F. (2005), Quantifying root system quality of nursery seedlings and relationship to outplanting performance. New Forests 30(2-3), 295-311. https://doi.org/10.1007/s11056-005-7480-y.

[10] Apshara, E., Jose, C. T. (2013), Genotypic variations in chlorophyll fluorescence and stomatal conductance of cocoa in relation to drought tolerance. Journal of Plantation Crops 41(1).

[11] Daymond, A., J., Hadley, P. (2004), The effects of temperature and light integral on early vegetative growth and chlorophyll fluorescence of four contrasting genotypes of cacao (Theobroma cacao). Ann. Appl. Bio. 145, 257-262.

[12] Vinya, R., Malhi, Y., Brown, N. D., Fisher, J. B., Brodribb, T., Aragão, L. E. O. C. (2018), Seasonal changes in plant-water relations influence patterns of leaf display in Miombo woodlands: Evidence of water conservative strategies. Tree Physiology 39(1), 104-112. https://doi.org/10.1093/treephys/tpy062.

[13] Chidumayo, E. N. (2001), Climate and phenology of savanna vegetation in Southern Africa. Journal of Vegetation Science 12(3), 347-354. https://doi. org/10.2307/3236848.

[14] Borchert, R. (1994), Soil and stem water storage determine phenology and distribution of tropical dry forest trees. Ecology 75(5), 1437-1449. https:// doi.org/10.2307/1937467. 
[15] Karban, R. (2017), Leaf drop in evergreen Ceanothus velutinus as a means of reducing herbivory. Ecology 89(9), 2446-2452. Wiley (on behalf of the Ecological Society of America Stable). Available at: http://www.jstor.org/ stable/27650783.

[16] Carr, M. K. V., Lockwood, G. (2011), The water relations and irrigation requirements of cocoa (Theobroma cacao l.): A review. Experimental Agriculture 47(2011), 653-676. https://doi.org/10.1017/S0014479711000421.

[17] Mulcahy, D. N., Mulcahy, D. L., Dietz, D. (2013), Biochar soil amendment increases tomato seedling resistance to drought in sandy soils. Journal of Arid Environments 88, 222-225. https://doi.org/10.1016/j.jaridenv.2012.07.012.

[18] Lu, S., Sun, F., Zong, Y. (2014), Effect of rice husk biochar and coal fly ash on some physical properties of expansive clayey soil (Vertisol). Catena 114, 37-44. https://doi.org/10.1016/j.catena.2013.10.014.

[19] Bali, R. S., Chauhan, D. S., Todaria, N. P. (2013), Effect of growing media, nursery beds and containers on seed germination and seedling establishment of Terminalia bellirica (Gaertn.) Roxb., a multipurpose tree. Tropical Ecology 54(1), 59-66. 